\title{
Die Individualität der Wirklichkeit und der Arzt
}

Rolf Adler

\section{Das Erschaffen einer «gemeinsamen Wirklichkeit» (auch zwischen Arzt und Patient) ist der sozialen Interaktion vorbehalten.}

Korrespondenz:

Prof. em. Dr. med. Rolf H. Adler Leiserenweg 4 CH-3122 Kehrsatz
Vor wenigen Tagen sah und hörte ich Mani das Lied «I der Ysebahn sitze die einten esoo ...» vortragen. Ich schreibe «Mani», weil er durch Progymnasium und Gymnasium ein Klassenkamerad war.

Manis Lied vom Zug nach Rorschach gibt Anlass zu Überlegungen über die Arzt-Patienten-Beziehung. Welche Reisenden sehen die Umgebung richtig, wahrheitsgemäss? Diejenigen mit Blick in Fahrtrichtung oder diejenigen mit Blick in die Richtung, aus der der Zug kommt? Der Kondukteur ist zufrieden, wenn er die in Streit Geratenen - «Si gäben änand mit Schirme ufs Dach...» - in Rorschach abliefern kann. Der Arzt aber sollte aus dem Liedinhalt schliessen, dass die Wirklichkeit individuell ist. Das Erschaffen einer "gemeinsamen Wirklichkeit» (auch zwischen Arzt und Patient) ist der sozialen Interaktion vorbehalten.

Die «individuelle Wirklichkeit» ist eine Funktion der Stimmung, der momentanen Bedürfnisse, der Persönlichkeit, der Selbstideale, des Gewissens und der eigenen Entwicklungsgeschichte. Die Synthese dieser Vorgaben bestimmt, welche Aspekte der Umgebung ein Individuum auswählt und als bedeutsam erfährt und verarbeitet. Es gestaltet also seine individuelle, persönliche Hülle, Umgebung wird damit zu Umwelt. Es konstruiert sie. Die Wahrheit werden wir nie erfassen. Wir können lediglich möglichst widerspruchsfreie Theorien der Umgebung, zu der auch der

eigene Körper zählt, entwerfen und sie durch weitere Beobachtungen bestätigen. Sonst müssen wir die Theorien verwerfen, ein schmerzlicher Verzicht, den beispielsweise die Anhänger der Homöopathie nicht ertragen. Semiotisch nennen wir die Instanz, deren Aufgabe darin besteht, der Umgebung Unterschiede abzuluchsen, die für das Individuum den Unterschied ausmachen, den Interpretanten. In der Psychoanalyse spricht man an dieser Stelle von einer Aufgabe des Ich. Ausschnitten aus der Umgebung werden also Bedeutungen aufgeprägt, aus der Umgebung eine je spezifische Umwelt konstruiert.
Leider verfahren die meisten Ärzte mit ihren Patienten so, wie wenn sie und ihre Patienten von einer gemeinsamen Wirklichkeit ausgingen. Sie unterbrechen die Schilderung eines Patienten nach der Eröffnung des Gesprächs schon nach durchschnittlich 18 Sekunden und verhindern damit, dass der Patient ihnen seine individuelle Wirklichkeit erklären kann. Die Ärzte vermeinen, damit auch Zeit zu sparen. Was dabei geschehen kann, hat mir während der Supervision ein Hausarzt geschildert:

Ein 57-jähriger Arbeiter, der vor vier Jahren einen Herzinfarkt erlitten hat, zäh und unerschrocken aber trotzdem Arbeiten im steil abfallenden Wald verrichtet, meldet sich bei ihm wegen einer Störung beim Sehen. Der Hausarzt bestätigt die Sehstörung und schickt ihn sofort zum Neurologen, der ein NotfallMRI verordnet. Der Patient meldet sich im Spital und wird nach der Aufnahmeprozedur in einen Raum geleitet, den er im Rückblick dem Hausarzt als Leichenhalle beschreibt. Die Ärzte bitten ihn, sich auf den Tisch der Apparatur zu legen. Der Mann wird unruhig, dann panisch. Die Ärzte fassen ihn an, um ihn in die nötige Körperlage zu bringen. Er schlägt jetzt um sich. Zwei Polizisten werden gerufen. Sie ringen den Mann nieder und ein Arzt injiziert ein Neuroleptikum. Dann wird das MRI durchgeführt. Ein Atemstillstand tritt ein, der Patient wird intubiert und in die Intensivstation gebracht, wo er eine Woche lang bleibt.

Nach der Spitalentlassung bittet der Patient um Erklärungen für die Geschehnisse. Die MRI-Ärzte, die Polizei, der administrative Direktor und schliesslich der Ärztliche Direktor lehnen eine Verantwortung ab. So bittet schliesslich der Hausarzt den Patienten und den Ärztlichen Spitaldirektor zu einem klärenden Gespräch zu dritt in seine Praxis. Das Gespräch findet statt. Dabei hört der Chefarzt dem Kranken wenig zu, unterbricht ihn oft und lehnt jegliche Verantwortung wieder ab. Der Patient wäre mit einer Entschuldigung zufrieden gewesen. Jetzt droht ein Gerichtsfall.

Was lehrt uns der einfühlsame, grossartig einfach tiefe Wahrheiten im Lied ausdrückende Mani Matter? Die Wirklichkeit ist individuell; es gibt keine Wahrheiten. Für den Arzt heisst es, dass er einen Zugang zur individuellen Wirklichkeit des Patienten suchen muss. Im Fall des geschilderten Patienten beispielsweise mit der Frage: Wie ist es für Sie, hier diese Untersuchung über sich ergehen zu lassen? 